\title{
Comparison of Bronchodilator Response of Nebulized Salbutamol with Nebulized Salbutamol and Ipratropium Bromide in Patients with Acute Exacerbation of Advanced COPD
}

\author{
Md. Aminul Hasan, ${ }^{1}$ Sonia Sheherin, ${ }^{2}$ Md. Amzad Hossain Sardar, ${ }^{3}$ Md. Ruhul amin, ${ }^{4}$ \\ Md. Ahsan Habib, ${ }^{5}$ Foysal Ahamed ${ }^{6}$
}

\begin{abstract}
Background: Patients admitted with acute exacerbation of Chronic Obstructive Pulmonary Disease (COPD) are often prescribed ipratropium bromide in combination with a $\beta_{2}$ agonist like salbutamol. Many studies have not shown any benefit in adding ipratropium bromide to salbutamol in acute exacerbations of COPD.
\end{abstract}

Objectives: To compare the response of combination therapy with two drugs vs. salbutamol alone in the treatment of acute exacerbations of COPD during hospital admission.

Materials and Methods: This cross-sectional comparative study was conducted among one hundred patients of acute exacerbation of COPD admitted in Rajshahi Medical College Hospital from January 2012 to July 2012. The patients were randomly allocated to receive either solution-1 (salbutamol $5 \mathrm{mg}$ alone) or solution-2 (salbutamol $5 \mathrm{mg}$ plus ipratropium bromide $500 \mu \mathrm{gm}$ ) (all four times a day) on admission. All other treatment was prescribed at the discretion of the attending physician.FEV1 and FVC values at baseline, at 1 hour, on day 1, day three, and on discharge date were assessed. Patients completed a subjective symptom score at 1 hour, Day 1, Day 3, and on the discharge date. Length of stay in hospital was assessed.

Results: There was no significant difference in spirometric values at 1 hour, Day 1, Day 3, and during discharge between the two groups. The subjective improvement was similar with both treatments. There was no difference between the two groups in the mean ( \pm SD) length of hospital stay (salbutamol $5.98( \pm 1.67$ ) days, salbutamol plus ipratropium bromide $5.8( \pm 1.39)$ days; $t=0.586$, $\mathrm{p}>0.05$ ).

Conclusion: The routine addition of nebulized ipratropium bromide to salbutamol appears to be of no benefit in the treatment of acute exacerbations of COPD.

Key words: Chronic Obstructive Pulmonary Disease, Salbutamol, Ipratropium Bromide.

TAJ 2021; 34: No-2: 56-63

\section{Introduction}

Chronic Obstructive Pulmonary Disease (COPD) is a respiratory disease that is characterized by chronic and progressive airflow obstruction, cough, shortness of breath, and sputum production. ${ }^{1}$ It affects more than $20 \%$ of adults over the age of 40 years, with those aged greater than 65 years being four times more likely to

${ }^{1}$ Assistant Professor, Department of Medicine, Shaheed Ziaur Rahman Medical College, Bogura.

${ }^{2}$ Radiotherapist, Department of Radiotherapy, Shaheed Ziaur Rahman Medical College Hospital, Bogura.

${ }^{3}$ Assistant Professor, Department of Medicine, Rajshahi Medical College, Rajshahi.

${ }^{4}$ Medical Officer (Dialysis), Department of Nephrology, Rajshahi Medical College Hospital, Rajshahi.

${ }^{5}$ Assistant Professor, Department of Medicine, Shaheed Ziaur Rahman Medical College, Bogura

${ }^{6}$ Assistant Professor, Department of Medicine, Mymensingh Medical College, Mymensingh. 
have COPD compared to those aged 45-64 years. ${ }^{2}$ Formerly a disease found only in men, the percentage of women who are being diagnosed with COPD rapidly increased from 2002-2012. ${ }^{2}$ According to the WHO, it is estimated that more than sixty-five million people are now living with moderate to severe COPD. ${ }^{3}$ In 2002, COPD was the fifth leading cause of death in the world, but by 2030 , it is projected to become the third leading cause of death worldwide. ${ }^{3}$ The overall prevalence of COPD in Bangladesh's total population is estimated at $4.32 \%$. Increasing age, sex, smoking, duration, and low socioeconomic condition were revealed as independent risk factors. ${ }^{5}$

The signs and symptoms of COPD can vary depending on which of the diseases, emphysema or bronchitis, is more prominent. Breathlessness, wheezing, chest tightness, chronic cough, and mucous production are the clinical symptoms associated with COPD. ${ }^{6}$ Spirometry is the most important lung function test to diagnose COPD ${ }^{6}$ It assesses the degree of airflow limitation and classifies COPD into four stages: mild, moderate, severe, and very severe. A postbronchodilator FEV1/FVC $<0.70$ (normal is $0.70-0.80$ ) on spirometry confirms a diagnosis. To date, there is no cure for COPD. However, it is a preventable and treatable disease. ${ }^{1}$

Treatment for COPD has remained purely on a symptomatic basis: relief of symptoms of breathlessness, through reducing airflow obstruction, relying mostly on the use of inhaled bronchodilator therapy including $\beta_{2}$ adrenergic agonists and anticholinergics. The recent introduction of long-acting $\beta_{2}$ agonists (LABA) and long-acting anticholinergics (LAA) has led to an improvement in the management of patients with COPD, allowing for more sustained bronchodilation and symptoms relief. ${ }^{7}$ Inhaled bronchodilators are the foundation of pharmacotherapy for COPD because of their capacity to alleviate symptoms, decrease exacerbations of the disease and improve the quality of life. ${ }^{8,9,10,11}$ These drugs also improve airflow and hyperinflation, ${ }^{12,13,14,15,16}$ thereby, decreasing the work of breathing and improving exercise tolerance. Patients admitted to the hospital with an acute exacerbation of chronic obstructive pulmonary disease are usually treated with a high dose of $\beta_{2}$ agonists as part of their therapy. It is now commonplace for the patient to receive, in addition, nebulized ipratropium bromide with obvious additional cost. This is logical pharmacologically as ipratropium has a different mode of action, inhibiting vagally mediated bronchomotor tone. ${ }^{17}$ There is evidence that adding ipratropium bromide to a nebulized $\beta_{2}$ agonist is valuable in the long term management of COPD. ${ }^{18-20}$ It has been known for some years that atropine-like drugs may be more effective in remission of airway obstruction. ${ }^{21,22}$ The aim of this study is to compare the response to $\beta_{2}$ agonists alone with $\beta_{2}$ agonists and anticholinergics in patients with COPD.

\section{Materials and Methods}

This comparative cross-sectional study was carried out in the Medicine units of Rajshahi Medical College Hospital, Rajshahi, from January 2012 to July 2012.Consecutive 100 patients having an acute exacerbation of COPD who fulfilled the inclusion and exclusion criteria had been enrolled in this study. Data were collected by detailed history taking, physical examination, and spirometric measurements, which were performed in a prefixed questionnaire form or data collection sheet after taking the informed consent of the patient.

On admission, the patient was allocated purposefully to receive either solution-1 (salbutamol $5 \mathrm{mg} / 5 \mathrm{ml}$ ) four times daily or solution-2 (salbutamol $5 \mathrm{mg} / 5 \mathrm{ml}$ plus ipratropium bromide $500 \mu \mathrm{gm} / 2 \mathrm{ml}$ ) four times daily. These drugs were administered by an air-driven nebulizer at a flow rate of $81 / \mathrm{min}$ until the chamber was dry. The combination therapy was given as a mixture. All other medication was prescribed at the attending physician's discretion according to the usual management plan. Spirometric values (best of three attempts) were measured at 1 hour, Day 1 , Day 3, and on the discharge date. A simple subjective score was recorded. ${ }^{23}$ The patient was assessed whether they felt better, worse, or the same as the previous day. To ensure uniform treatment, packages were prepared and coded by the investigator himself. These packages were then dispensed by the investigator. 


\section{Results}

Table 1: Demographic characteristics of the patient in solution 1 and solution 2

Demographic characteristics Solution $1(\mathbf{N}=50)$

\begin{tabular}{|c|c|c|c|c|c|}
\hline & & $\mathbf{N}(\%)$ & $\begin{array}{l}\text { Mean } \\
\pm \text { SD }\end{array}$ & $\mathbf{N}(\%)$ & $\begin{array}{l}\text { Mean } \\
\pm \text { SD }\end{array}$ \\
\hline \multirow[t]{3}{*}{ Age } & $<50$ yrs. & 7 (14) & & $10(20)$ & \\
\hline & $50-60$ yrs. & $16(32)$ & 58.9 & $11(22)$ & 57.78 \\
\hline & $>60 \mathrm{yrs}$ & $26(54)$ & \pm 7.68 & $29(58)$ & \pm 8.06 \\
\hline \multirow[t]{2}{*}{ Sex } & Male & $50(100)$ & & $49(98)$ & \\
\hline & Female & $0(0)$ & & $1(2)$ & \\
\hline \multirow[t]{6}{*}{ Occupation } & Farmer & $29(58)$ & & $25(50)$ & \\
\hline & Laborer & $11(22)$ & & $13(26)$ & \\
\hline & Businessman & $5(10)$ & & $4(8)$ & \\
\hline & Service & $3(6)$ & & $4(8)$ & \\
\hline & Housewife & $0(0)$ & & $1(2)$ & \\
\hline & Others & $2(4)$ & & $3(6)$ & \\
\hline
\end{tabular}

Ages of the patients were of varying range from 42 to 76 years, and the mean $( \pm \mathrm{SD})$ age was $58.9( \pm 7.68)$ years for solution-1 group and 57.78( \pm 8.06$)$ years for solution-2 group.

There were no female patients in solution-1 group, but in solution-2 group one patient was female.

The main occupation of the patients in both groups was farmer. There was one house-wife in solution-2 group (Table 1)

Table 2: Distribution of patients according to the hospital stay

\begin{tabular}{llll}
\hline Hospital stay & $\begin{array}{l}\text { Solution } 1(\mathrm{~N}=50) \\
\text { Mean } \\
( \pm \mathrm{SD})\end{array}$ & $\begin{array}{l}\text { Solution 2(N=50) } \\
\text { Mean } \\
( \pm \mathrm{SD})\end{array}$ & $\begin{array}{l}\mathrm{t} \\
(\mathrm{p})\end{array}$ \\
\hline 5.98 & 5.8 & 0.586 \\
$( \pm 1.67)$ & $( \pm 1.39)$ & $(>0.05)$ \\
\hline
\end{tabular}


The mean hospital stay in solution-1 and solution-2 groups were 5.98( \pm 1.67$)$ and 5.8( \pm 1.39$)$, respectively. No difference was observed in the hospital stay between the two groups $(\mathrm{t}=0.586$, $(\mathrm{p}>0.05)$. (Table-02)

Table 3: Subjective improvement over hospital stay

\begin{tabular}{|c|c|c|c|}
\hline Time & $\begin{array}{l}\text { Solution } 1(\mathrm{~N}=50) \\
\mathrm{n}(\%)\end{array}$ & $\begin{array}{l}\text { Solution } 2(\mathrm{~N}=50) \\
\mathrm{n}(\%)\end{array}$ & $\begin{array}{l}x^{2} \\
(p)\end{array}$ \\
\hline \multicolumn{4}{|l|}{ At hour-1 } \\
\hline Worse & $8(16)$ & $10(20)$ & 0.271 \\
\hline Same & $42(84)$ & $40(80)$ & $(>0.05)$ \\
\hline \multicolumn{4}{|l|}{ At day-1 } \\
\hline Worse & $15(30)$ & $10(20)$ & 1.333 \\
\hline Same & $35(70)$ & $40(80)$ & $(>0.05)$ \\
\hline \multicolumn{4}{|l|}{ At day-3 } \\
\hline Worse & $5(10)$ & $2(4)$ & 4.339 \\
\hline Same & $8(16)$ & $3(6)$ & $(>0.05)$ \\
\hline Better & $37(74)$ & $45(90)$ & \\
\hline \multicolumn{4}{|l|}{ At discharge } \\
\hline Better & $50(100)$ & $50(100)$ & \\
\hline
\end{tabular}

Subjective symptoms at hour-1in both groups were worse 8(16\%), $10(20 \%)$, same $42(84 \%), 40(80 \%)$ respectively. $\mathrm{x}^{2}$ value was $0.271(\mathrm{p}>0.05)$. At day-1in both groups were worse $15(30 \%), 10(20 \%)$, same $35(70 \%), 40(80 \%)$ respectively. $\mathrm{x}^{2}$ value was 1.333 (p>0.05).At day-3in both groups were worse $5(10 \%)$, $2(4 \%)$, same $8(16 \%), 3(6 \%)$, and better 37(74\%), 45(90\%) respectively. $x^{2}$ value was $4.339(\mathrm{p}>0.05)$ and during discharge in both groups were better 50(100\%) and 50(100\%) respectively. No difference was observed in the subjective improvement between the two groups (Table-03).

Figure 1: Mean change in FEV1 over time $(\mathrm{N}=100)$

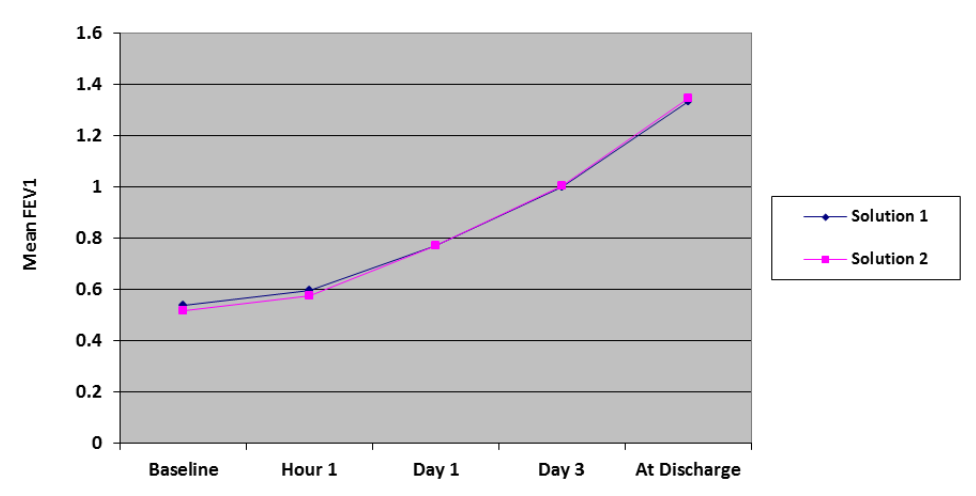


No significant difference was observed between solution-1 \& solution-2 groups in FEV1 at baseline $(\mathrm{t}=0.888, \mathrm{df}=98, \mathrm{p}>0.05)$, at 1 hour $(\mathrm{t}=0.797, \mathrm{df}=98, \mathrm{p}>0.05)$, at day $1(\mathrm{t}=-0.021, \mathrm{df}=98, \mathrm{p}>0.05)$, at day $3(\mathrm{t}=-0.051, \mathrm{df}=98, \mathrm{p}>0.05)$ and during discharge $(\mathrm{t}=-0.833, \mathrm{df}=98, \mathrm{p}>0.05)$. (Figure 01)

Figure 2: Mean improvement in FEV1 over time $(\mathrm{N}=100)$

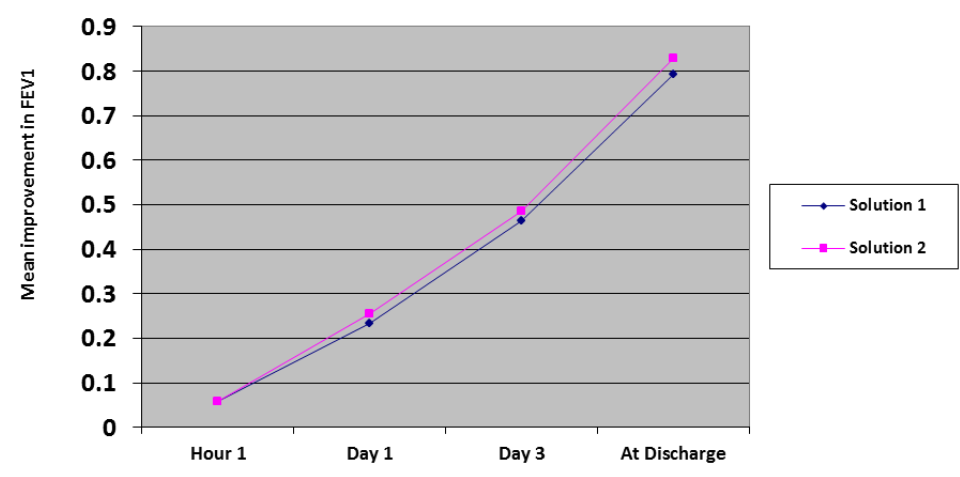

There was no significant difference in improvement between solution-1 \& solution-2 groups in FEV1 after hour1 $(\mathrm{t}=-0.091, \mathrm{df}=98, \mathrm{p}>0.05)$, after day $1(\mathrm{t}=-0.838, \mathrm{df}=98, \mathrm{p}>0.05)$, after day $3 \quad(\mathrm{t}=-$ $0.633, \mathrm{df}=98, \mathrm{p}>0.05)$ and during discharge $(\mathrm{t}=-0.833, \mathrm{df}=98, \mathrm{p}>0.05)($ Figure 02).

Figure 3: Mean change in FVC over time $(\mathrm{N}=100)$

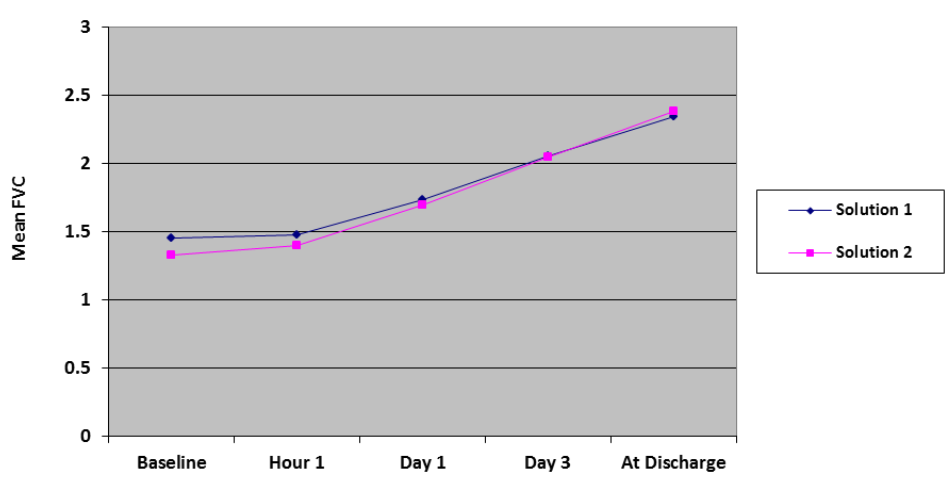

No significant difference was observed between solution-1 \& solution-2 groups in FVC at baseline $(\mathrm{t}=1.520, \mathrm{df}=98, \mathrm{p}>0.05)$, at Hour $1(\mathrm{t}=0.818, \mathrm{df}=98, \mathrm{p}>0.05)$, at day $1(\mathrm{t}=-0.539, \mathrm{df}=98, \mathrm{p}>0.05)$, at day $3(\mathrm{t}=-0.149, \mathrm{df}=98, \mathrm{p}>0.05)$ and during discharge $(\mathrm{t}=-0.575, \mathrm{df}=98, \mathrm{p}>0.05)$. (Figure 03) 
Figure 4: Mean improvement in FVC over time $(\mathrm{N}=100)$

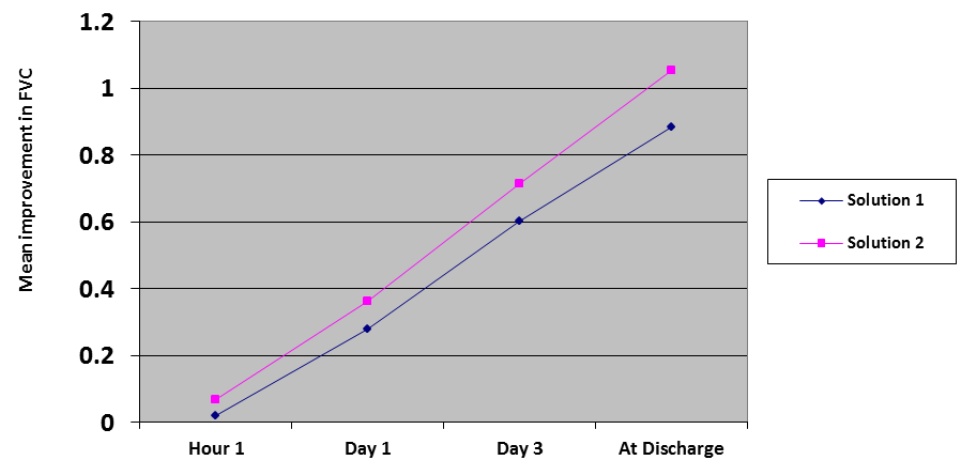

There were no significant difference in improvement between solution-1 \& solution-2 groups in FVC after 1 hour $(\mathrm{t}=-1.418, \mathrm{df}=98, \mathrm{p}>0.05)$, after day $1(\mathrm{t}=-1.958, \mathrm{df}=98, \mathrm{p}>0.05)$, after day $3 \quad(\mathrm{t}=-$ $1.826, \mathrm{df}=98, \mathrm{p}>0.05)$ and during discharge $(\mathrm{t}=-1.802, \mathrm{df}=98, \mathrm{p}>0.05)$. There was no age related significant difference between two groups (F-0.927, df-4, p>0.05). (Figure 04)

There was no significant age-related difference observed between the two groups (F-0.927, df-4, p>0.05).

\section{Discussion}

In our study, the mean age of patients of salbutamol group and salbutamol plus ipratropium bromide groups were $58.9( \pm 7.68)$ and $57.78( \pm 8.06)$, respectively. The maximum number of patients, i.e., $27(54 \%)$ in the salbutamol group and $29(58 \%)$ in the salbutamol plus ipratropium group, were above 60 years of age. But a study conducted by Moayyedi et al. ${ }^{22,}$ the mean age was 70.4 and 67.8. Lower age group was observed in our study. Presentation of COPD in earlier age groups in our country may be explained by lower socioeconomic conditions and undernutrition. Most of our patients were farmer.

There was only one female patient in the salbutamol plus ipratropium group. Although Brown IG and colleagues found a higher proportion of female patients with COPD (33\%). ${ }^{23}$ But we had only one female in our study (1\%). That is probably because of the lesser prevalence of smoking in females in our population.

No significant difference was observed between $\beta_{2^{-}}$ agonist and $\beta_{2}$-agonist plus anticholinergic group in mean hospital stay in our study. Similar findings were observed by Brown IG et al. ${ }^{23}$ and Moayyedi et al. ${ }^{22}$ But, shorter duration in-hospital stay was observed by
Shrestha et $\mathrm{al}^{24}$ in which study despite salbutamol, Isoetharine was used.

It was found that both salbutamol and ipratropium bromide were effective in acute exacerbation and stable COPD. ${ }^{18,23,25}$ Although a study has shown that ipratropium bromide was more effective than albuterol. No significant synergistic or additive improvement with salbutamol and ipratropium bromide in pulmonary function was observed in our study. Which findings are similar to most of the studies. ${ }^{18,23,26}$ Although some have demonstrated significant improvement with combination therapy in terms of airway obstruction in acute exacerbation of COPD and in stable COPD. ${ }^{27-29}$

The combination of salbutamol and ipratropium bromide appeared to give no significant additional benefit compared with salbutamol alone during the routine inpatient treatment of an acute exacerbation of COPD. No difference was observed in spirometric values, subjective symptom scores, duration of hospital stay, or the number of days on a nebulizer between the two groups. This is in contrast to findings in stable COPD, although results are not consistent. Many trials in stable outpatients with COPD have shown combination therapy to be beneficial $^{30-31}$, although some suggest that any improvement is small. Furthermore, some researchers have shown that 
ipratropium bromide alone is as effective as either salbutamol alone or combination therapy. ${ }^{32}$

\section{Conclusion}

We conclude that the addition of ipratropium to salbutamol confers no significant benefit in the routine management of the hospital in patients with acute exacerbations of COPD. We consider that these results apply only to acute exacerbations, and the situation with respect to long-term domiciliary treatment is different. However, no significant substantial improvement was observed with the addition of ipratropium bromide in our study. So in the treatment of an acute exacerbation of COPD, it would seem reasonable to advise adding nebulized ipratropium bromide to a $\beta_{2}$ agonist only when a patient is not responding satisfactorily.

\section{References}

1. Rabe KF, Hurd S, Anzueto A, Barnes PJ, Buist SA, Calverley $\mathrm{P}$, et al. Global strategy for the diagnosis, management and prevention of chronic obstructive pulmonary disease: GOLD executive summary. Am J Respir Crit Med 2007; 176: 532-35

2. Chronic respiratory disease. World Health Organization. 2010: 4

3. Global Initiative for Chronic Obstructive Lung Disease (2009).Global Strategy for Diagnosis, Management and Prevention of COPD Executive Summary. Available from http:// www.goldcopd.org2009

4. Report on National COPD Study, 2007. Burden of Obstructive Lung Diseases in Bangladesh (BOLD -BD). Bangladesh Lung Foundation.2010: 19

5. Pauwels RA, Buist AS, Ma P, Jenkins CR, Hurd SS. Global strategy for the diagnosis, management, and prevention of chronic obstructive pulmonary disease: National Heart, Lung, and Blood Institute and World Health Organization Global Initiative for Chronic Obstructive Lung Disease(GOLD): executive summary. Respir Care 2001; 46:798-825.

6. Appeleton S. Smith B, Veale A, Bare A. Long-acting beta2 agonists for chronic obstructive pulmonary disease.Cochrane database Syst.2000 Reu, 2:CD001104.

7. Higgins BG, Powell RM, Coopers, Tatters field AE. Effect of salbutamol and ipratropium bromide on airway caliber and bronchial reactivity in asthma and chronic bronchitis. Eur Respir J 1991; 4:415-20.

8. Dahl R, Greefhorst LA, Nowak D et al. Inhaled Formoterol dry powder versus ipratropium bromide in chronic obstructive pulmonary disease. Am J Respir Crit Care Med 2001; 164:778- 84.
9. Rennard SI, Anderson W, Zuwallack R, et al. Use of a long acting inhaled beta- 2 adrenergic agonists, Salmeterol xinafoate, in patients with chronic obstructive pulmonary disease. Am J Respir Crit Care Med 2001; 163:1087-92.

10. Casalburi R, Mahler DA,Jones PW et al. A long-term evaluation of once daily inhaled Tiotropium in chronic obstructive pulmonary disease. Eur Respir J 2002;19:217-24

11. Belman MJ, Botnick WC, Shin JW. Inhaled bronchodilators reduce dynamic hyperinflation during exercise in patient with chronic obstructive pulmonary disease. Am J Respir CritCare Med 1996; 153:967-75.

12. Combivent Inhalation Aerosol Study Group. In chronic obstructive pulmonary disease, a combination of ipratropium and albuterol is more effective than either agent alone: an 85-day multicenter trial chart 1994:105:1411-9.

13. Ram FS, Sestini P. Regular inhaled short acting beta-2 agonists for the management of stable chronic obstructive pulmonary disease; Cochrane systematic review and meta-analysis, thorax 2003; 58:580-4.

14. Petric GR, Palmer KN. Comparison of aerosol ipratropium bromide and salbutamol in chronic bronchitis and asthma. Br Med J 1975:1:430-2.

15. Fabbri LM, Hurd SS. Global strategy for the diagnosis, management and prevention of COPD; 2003 update Eur respire J 2003; 22:1-2.

16. Nieman J, Michel S. Anticholinergic,antimuscarinic bronchodilators. Am Rev Respir Dis 1984; 129:856-70.

17. O’Driscoll BR, Horsley MG, Tayler RS, Chambers DK, Bernstein A. Nebulized salbutamol with and without ipratropium bromide in acute airflow obstruction, Lancet1989; i:1418-20.

18. Morrison JFJ, Jones PC, Muers MF. Assessing physiological benefit from domiciliary nebulized bronchodilators in severe airflow limitation. Eur Respir J 1992; 5:424-9.

19. Goldman JM, Teale C, Muers MF. Simplifying the assessment of patient with chronic airflow limitation for home nebulizer therapy. Respir Med 1992; 86:33-8.

20. Altounyan REC. Variation of drug action on airway obstruction in man. Thorax 1964; 19:406-15.

21. Teale C, Morrison JFJ, Muers MFM, Pearson SB. Response to nebulized ipratropium bromide and terbutaline in acute severe asthma. Repir Med 1992; $86: 215-8$. 
22. Moayyedi PJ Congleton RL Page SB Pearson MF Muers. Comparison of nebulized salbutamol and ipratropium bromide with salbutamol alone in the treatment of chronic obstructive pulmonary disease. Thorax 1995; 50:834-837.

23. Brown IG, Chan CS, Kelly CA, Dent AG, Zimmerman PV. Assessment of the clinical usefulness of nebulized ipratropium bromidein patients with chronic airflow limitation. Thorax 1984; 39:272-6.

24. Shrestha M, O'Brien T, Haddox R,et al.Decreased duration of emergency department treatment of COPD exacerbations with the addition ofipratropium bromide to beta-agonists therapy. Ann Emerg Med 1991; 20:1206-1209.

25. Koutsogiannis Z, Kelly AM. Does high dose ipratropium bromide added tosalbutamol improve pulmonary function for patients with COAD in the emergency department? Aus N Z Med J 2000; 30:41-7.

26. Van Noord JA,Bommer AM,Akveld MLM,et al.Longterm treatment of chronicobstructive pulmonary disease with Salmeterol and the additive effect of ipratropium. Eur Respir J 2000; 15:878-885.
27. Sheldon R, Wayland N, Cheryl Copeland,et al. A comparison of the effect of ipratropium and albuterol in the treatment of COPD.Arch Intern Med1989; 149:544547.

28. Jill P, Jeffrey P, Daniel G et al. A comparison of the effects of ipratropiumbromide and metaproterenol sulfate in acute exacerbations of COPD. Chest 1990; 98:835-39.

29. Lloberes P, Ramis L, Serra J,et al. Effect of three bronchodilators during an exacerbation of COPD. Eur Respir J 1988; 1:536-539.

30. Roger B, Michael B, Thomus C,et al.In chronic obstructive pulmonary disease, a combination of ipratropium and albuterol is more effective than either agent alone. Chest 1994; 105:1411-1419.

31. Crane J, Gamble S, Purdie G. Comparison of a fenoterol/ ipratropium combination with salbutamol form metered dose inhalers in subjects with chronic partially reversibleairways obstruction. NZ Med J 1987; 100:385-7.

32. Rebuck AS, Chapman KR, Abboud R, et al. Nebulized airways disease in the emergency room. Am J Med 1987; 82:59-64.

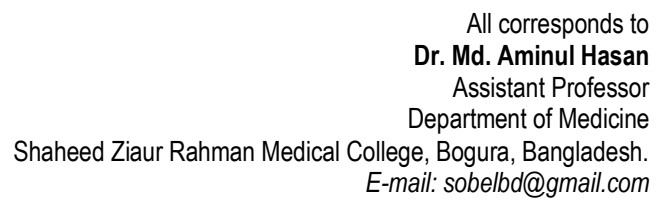

